\title{
PEA PROTEINS IMMUNOTHERAPY IN PEANUT ALLERGIC MICE MODEL
}

\author{
A. Szymkiewicz* and J. ChudziK-KozŁowska \\ Division of Food Science, Institute of Animal Reproduction and Food Research of Polish Academy of Sciences, \\ 10-748 Olsztyn, Tuwima 10 Street, Poland
}

(Received: 17 May 2012; accepted: 17 January 2013)

\begin{abstract}
Mice (Balb/c), with peanut allergy induced, were subjected to desensitization therapy with the use of pea protein extract (PE) or isolated globulin fractions: legumin (PL) and vicilin (PV). B- and T-cell responses to peanut proteins were analysed by determination of the IgE, IgG1, and IgG2a antibody levels in plasma and the concentration of IL4, IFN-gamma and IL-10 cytokines secreted by isolated splenocytes.

Conducted studies have demonstrated that immunotherapy with proteins resulted in the decrease of total $\operatorname{IgE}$ and peanut-specific IgG1 levels and significantly enhanced synthesis of peanut-specific IgG2a in plasma (ELISA method) and at the cellular level (ELISPOT type B). A successful and effective immunotherapy is related to the shift in profile of lymphocytes from Th2 subpopulation towards Th1 subpopulation. In our studies significant increase in the activity of Th1 lymphocytes was observed in groups desensitized with pea protein extracts (PE) and pea legumin fraction (PL). In these groups, significant statistic decrease in IL-4 secreted and increase in IL-10 level were found.

Desensitization method with the use of pea proteins being suggested in the presented studies can be an alternative method for specific immunotherapy for people, especially with strong allergic reaction to peanuts; however, this method needs further studies with mouse model.
\end{abstract}

Keywords: peanut hypersensitivity, specific immunotherapy, cross-reactivity, pea proteins, animal model

Peanut allergy is one of the most serious disorders among the immediate hypersensitivity reactions and it appears to be a growing problem. The most common treatment of food allergy is exclusion of the component causing hypersensitivity from diet. However, in case of allergy to peanuts, this method is not suitable due to the possible occurrence of peanuts in foods, cosmetics and pharmaceutical products. Another problem is that traces of peanut allergens are sufficient to induce strong reaction (Hourihane et al., 1997; BlumCHEN et al., 2010). Mechanism of peanuts allergy is the subject of extended studies; however, there are still more questions than answers related to this aspect. Recent studies have proven that extracts from peanuts and nuts, contrary to milk or eggs, were able to activate complement system both in mice and people, which increased their ability to induce anaphylaxis (KHodoun et al., 2009). However, lack of definitive explanation of the mechanism of food hypersensitivity to peanuts limits therapeutic applications (Thyagarajan et al., 2010). Recently, a lot of attention has been focused on novel specific immunomodulatory therapies for food allergy, including oral immunotherapy (OIT) and sublingual immunotherapy (SLIT) (BLUMCHEN et al., 2010; FrEw, 2010). Allergen-specific immunotherapy (ASIT) has been reported to modify different aspects of the immune system, inducing shift of allergy-promoting Th2 cells to Th1 cells, epitope-specific T-cell anergy, and allergen-specific regulatory $\mathrm{T}$ cells that suppress the responses of effector T cells (ARPS et al., 1998; UERMÖSI et al., 2010).

\footnotetext{
* To whom correspondence should be addressed.

Phone.: +48 89 5234688; fax: +48 89 5240124; e-mail: a.szymkiewicz@pan.olsztyn.pl
} 
In the case of food allergies (especially concerning the peanut allergy), the oral administration of allergic proteins appears to be disapproved by the medical staff. Mortal incidence due to incorrect peanut protein administration with subcutaneous injection was reported and thus the clinical experiment ceased (OPPENHEIMER et al., 1992). Recently the reports on the possibility of oral (BLUMCHEN et al., 2010) or sublingual administration of peanut proteins (KIM et al., 2011) have been published, however, the results of the experiment have not been confirmed and the effect of treatment appears to be dependent on a number of factors (Thyagarajan et al., 2010). The possibility of strong hypersensitivity reaction to peanut protein administered is significantly important. In such situations, it is recommended to use recombinant antigens or proteins that are characterized by a high degree of immunological similarity to allergens, resulting from considerable amino acids homology, but not having such high allergenic potential. Studies performed by PoNs and co-workers (2004) on animal model confirmed effectiveness of specific immunotherapy with soybean proteins in mice sensitized to peanuts. However, soybean also has strong allergenic properties that can be a risk, to some extent, during the therapy (SAVAGE et al., 2010). Additionally, a problem may exist for patients sensitised to peanuts that could previously consume soybean and already showed an immune response to it.

In the presented studies, specific immunotherapy was performed with the use of pea proteins to down-regulate the peanut-allergic responses in mice. The reason for the use of pea proteins is their high similarity with peanut proteins, especially globulin allergens (Ara h1 and Ara h3). Whereas, allergenicity of pea proteins is relatively low, which guarantee safeness of the method and promise that its usage in the future would not threat human life.

\section{Materials and methods}

\subsection{Mice and reagents}

Five-week-old female Balb/c mice purchased from Medical Research Centre, PAS, Warsaw, Poland, were maintained on legume-free feed. Standard guidelines for the care and use of animals were followed. Aluminium hydroxide gel was used as an adjuvant (Sigma A8222).

\subsection{Preparation of proteins}

The crude peanut extract $(\mathrm{PnE})$ and the crude pea extract $(\mathrm{PE})$ were prepared from defatted raw flour. The proteins $(1: 10, \mathrm{w} / \mathrm{v})$ were extracted with PBS for $2 \mathrm{~h}$ at room temperature. After centrifugation at $20000 \mathrm{~g}$ for $60 \mathrm{~min}$., the supernatant was filter-sterilized, frozen, and stored at $-20{ }^{\circ} \mathrm{C}$ until further use. Protein concentrations were determined using the Bradford's method with BSA as a standard. Reducing SDS-PAGE from the extracts showed protein bands ranging from 6.5 to approximately $100 \mathrm{kDa}$ (not shown).

The pea globulins were extracted as previously described (FREITAS et al., 2000) and then fractioned by ammonium sulphate precipitation (MALEKI et al., 2000). Isolated pea legumin $11 \mathrm{~S}$ (PL) and pea vicilin 7S (PV) were purified by ion-exchange chromatography on the column packed with DEAE-Sepharose (Sigma DFF100) and lyophilized for further analyses. Purified fractions were eluted from the Biosep-SEC S-2000 column in the HPLC system as the single peaks (data not presented). 


\subsection{Mouse treatment protocol}

Peanut sensitization and challenge were preformed according to previously described protocol (Pons et al., 2004) with modifications. Sensitization was performed by intraperitoneal (IP) administration of $0.5 \mathrm{mg} \mathrm{PnE}$ in PBS with aluminium hydroxide $(0.3 \mathrm{ml}$ injected $)$ on days 1,7 , and 21. Desensitization was started two weeks after last sensitization dose and was given IP 3 times per week for 8 weeks. For peanut desensitized group the dose was used 0.5 $\mathrm{mg}$ of PnE; for pea desensitized groups: $1 \mathrm{mg}$ of PE; $0.5 \mathrm{mg}$ of PL and $0.25 \mathrm{mg}$ of PV (a dose selected according to the results found in previous experiments). For negative controls, sham-desensitized mice received PBS (group PnE/PBS). Naive mice received only PBS during sensitization and desensitization (group PBS/PBS). Challenges with PnE (1 mg in $0.3 \mathrm{ml}$ PBS) were started 2 weeks after the last desensitization dose. One day prior to extinguishing, sensitization to peanuts was assessed. The Local Care Use of Animal Committee (authorization 11/2007) approved animal handling and experimental procedures.

\subsection{Measurement of serum peanut-specific $\operatorname{Ig} G 1, \operatorname{Ig} G 2 a, \operatorname{IgE}$ and total $\operatorname{IgE}$ levels}

Tail vein blood was obtained during sensitization, treatments, and after desensitization. The blood was incubated for $1 \mathrm{~h}$ at $37^{\circ} \mathrm{C}$ and centrifuged at $14000 \mathrm{~g}$ for $10 \mathrm{~min}$. Then, the sera were collected and stored at $-20^{\circ} \mathrm{C}$.

The levels of peanut-specific IgG1, IgG2a, and IgE were measured by ELISA as previously described (LEE et al., 2001) with minor modifications. The plates were coated with $\mathrm{PnE}$ or PE at $20 \mu \mathrm{g} \mathrm{ml}^{-1}$ or globulin fractions at $10 \mu \mathrm{g} \mathrm{ml}^{-1}$. Sera were diluted at 1:50 000, 1:1000, and 1:5 for determination of IgG1, IgG2a, and IgE, respectively. After incubation for $2 \mathrm{~h}$ at $37^{\circ} \mathrm{C}$, the plates were washed with PBS-T (PBS with $0.05 \%$ Tween 20 ) and biotinylated rat anti-mouse IgG1 (550331, Becton Dickinson), IgG2a (553388, Becton Dickinson), or IgE (553414, Becton Dickinson) antibodies were added. After washing, streptavidin peroxidase conjugate (E2886, Sigma) was added (1 h incubation). The enzymatic reaction was developed with TMB (T5525, Sigma) for $15 \mathrm{~min}$. Absorbance was measured at $450 \mathrm{~nm}$ using SunriseTecan automatic reader.

Total IgE was determined by the ELISA assay according to the manufacturer's instructions (OptEIA ${ }^{\mathrm{TM}}$ Mouse IgE Set - 555248, Becton Dickinson). Serum was diluted at $1: 100$.

For each mouse, the immunoglobulin concentrations were the mean of triplicates.

\subsection{Spleen lymphocyte isolation, cytokine analysis}

Lymphocytes from spleen were isolated according to a standard method (Maddaloni et al., 2006). A total of $2 \times 10^{6}$ cells per $1 \mathrm{ml}$ were cultured in the complete medium at $37^{\circ} \mathrm{C}$ in the atmosphere of $5 \% \mathrm{CO}_{2}$. Complete cell culture medium containing RPMI 1640 medium (R8758, Sigma) was supplemented with 10\% heat inactivated newborn calf serum (N4762, Sigma), 1\% non-essential amino acids (M7145, Sigma), and 1\% penicillin-streptomycin solution (P4333, Sigma) (cRPMI). Cells were cultured in the medium without stimulation factor (negative control) or in the medium stimulated with $\mathrm{PnE}\left(100 \mu \mathrm{g} \mathrm{m} \mathrm{l}^{-1}\right)$, peanut globulin fractions $\left(50 \mu \mathrm{g} \mathrm{ml}^{-1}\right)$, or ConA $\left(5 \mu \mathrm{g} \mathrm{ml}^{-1}\right)$ (positive control).

Levels of IFN-gamma, IL-4, and IL-10 in the supernatants of 48-h cultures were determined in triplicates using commercial enzyme-linked immunosorbent assay (ELISA) kit reagents according to the manufacturer's instructions (BD Pharmingen, Mississauga, Canada: Mouse IFN- $\gamma$ ELISA set - BD 555138, Mouse IL-4 ELISA set - BD 555232, and Mouse IL10 ELISA set - BD 555252). 


\subsection{B cell Ab ELISPOT}

For antibody-formatting cells (AFC), counting IgG antigen-specific ELISPOT analyses were performed according to a standard method (MADDALONI et al., 2006). The MultiScreen-IP plates (Millipore, MSIPS4510) were coated with $20 \mu \mathrm{g} \mathrm{ml}{ }^{-1}$ of antigen in sterile PBS overnight at $4{ }^{\circ} \mathrm{C}$. The plates were blocked with cRPMI at $37^{\circ} \mathrm{C}$ for $1 \mathrm{~h}$, and next washed five times with PBS. A total of $100 \mu$ of cells from spleen at $1 \times 10^{5}$ concentrations were added to the wells. The plates were incubated overnight at $37{ }^{\circ} \mathrm{C}$ in $5 \% \mathrm{CO}_{2}$ atmosphere. To detect AFC response, anti-mouse IgG-HRP conjugates (A4416, Sigma) were added, and the plates were incubated overnight at $4{ }^{\circ} \mathrm{C}$. After washing, the reaction was developed with AEC substrate set (551951, Becton Dickinson) for $15 \mathrm{~min}$ at room temperature and then stopped with water. The spots were quantised with stereo zoom microscope (OLYMPUS, SZX 9) on the next day.

\subsection{Statistical analysis}

Data were analysed by one-way ANOVA, and then differences among means were analysed using Fisher-Protected Least Significant difference for multiple-comparison procedure. The level of significance was set at $\mathrm{P}<0.05$.

\section{Results and discussion}

Most studies to design new therapeutic methods in case of patients with strong peanut allergy have serious risk for the patient's health and life. Therefore, animal models are used for this aim (LeE et al., 2001; Pons et al., 2004). To sensitize Balb/c mice, peanut proteins (PnE) were administered at $0.5 \mathrm{mg}$ dose to mice. A dose higher than recommended, induced low production of IgE (Li et al., 2000) and could promote production of IgG2a (ARPs et al., 1998). Mice, in which peanut allergy induced an increased level of total IgE and peanut-specific $\mathrm{IgG1}$, were subjected to desensitization therapy with the use of pea proteins: pea proteins extract - PE $(1 \mathrm{mg})$ and isolated pea globulin fractions: $11 \mathrm{~S}$ legumin - PL $(0.5 \mathrm{mg})$ and $7 \mathrm{~S}$ vicilin - PV (0.25 mg). Pea proteins were selected since they have low allergenicity and high similarity to the amino acid sequences of peanut proteins (FÆSTE \& NAMORK, 2010).

Basic assumption of allergenic immunotherapy is the induction of peripheral tolerance to the injected allergens, which is demonstrated by reduction in the level of specific IgE, stimulation of production of blocking antibodies ( $\mathrm{G}$ class), decrease in the activity of effector cells, and switching of cytokine profile of T cells (FrEW, 2010). The effect of specific immunotherapy in our studies was the decrease in total IgE (Fig. 1) in mice serum, however, peanut-specific IgE did not show any significant statistic differences (not shown). The applied method of determination of specific-IgE may be the cause.

The lowest level of total IgE was found in the group desensitized with PnE (Fig. 1). Whereas IgE level was lower in group PE, there was no statistically significant difference in relation to the control group - placebo IT with PBS. In the group of mice to which PL was administered IgE level was lower in relation to the control group (PnE/PBS) and in the group PV was comparable to levels found in groups desensitized with peanut proteins. Desensitization with both peanut proteins and pea proteins reduced production of PnE-specific IgG1 in relation to the control group (Fig. 1). No statistically significant differences were observed between individual vaccinations. In the desensitized group with pea proteins (PE) significantly 
A

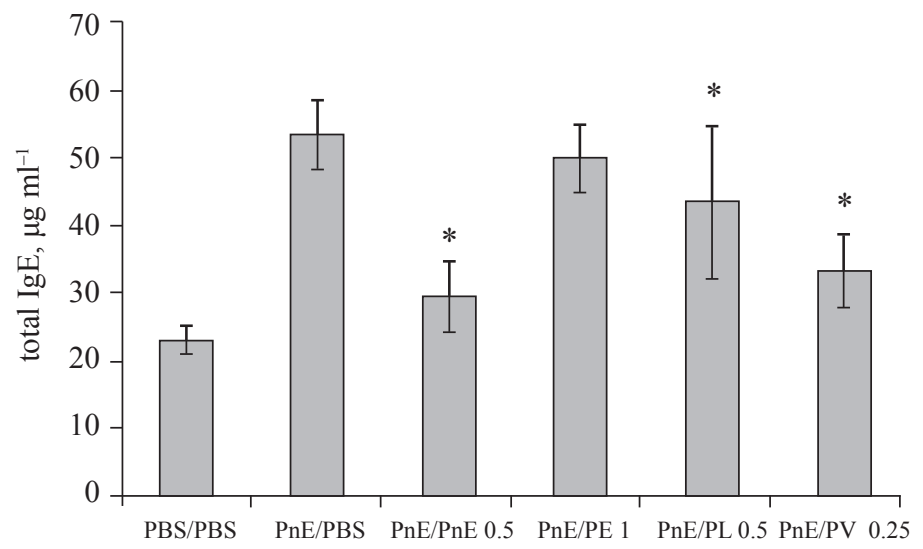

B

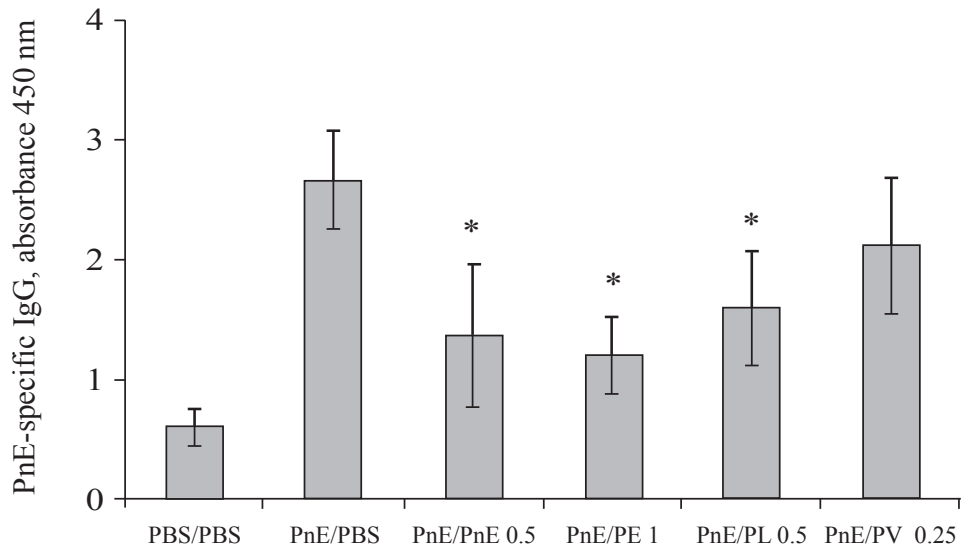

$\mathrm{C}$

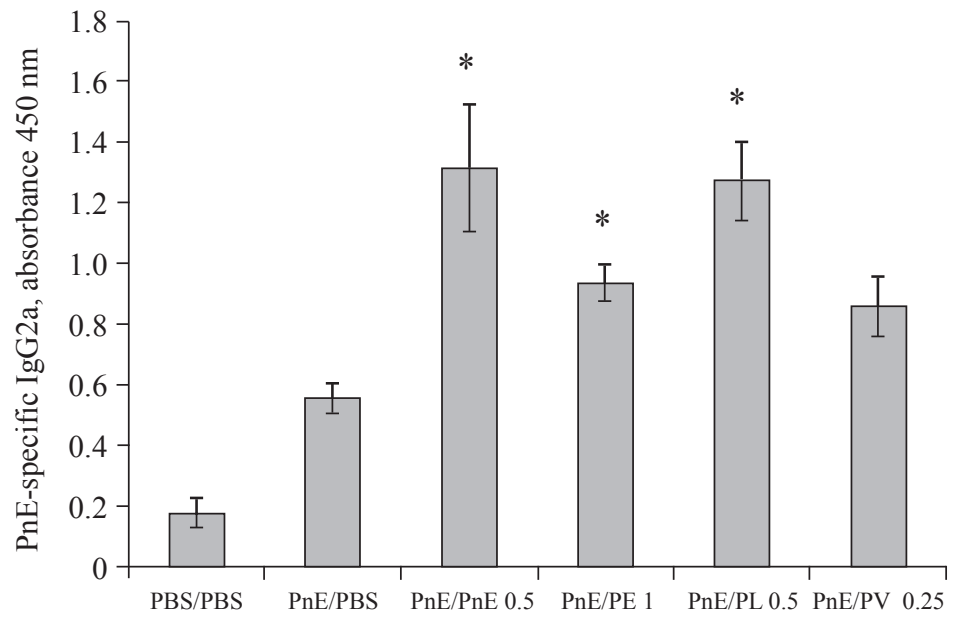

Fig. 1. Antibody levels in the serum of peanut-sensitized mice (PnE) after desensitization with: peanut proteins extract $0.5 \mathrm{mg}$ dose (PnE/PnE0.5); pea proteins extract $1 \mathrm{mg}$ dose (PnE/PE1); pea legumin $0.5 \mathrm{mg}$ dose (PnE/PL0.5); pea vicilin 0.25 mg dose (PnE/PV0.25); placebo IT with PBS (PnE/PBS); native mice sensitized and desensitized with PBS (PBS/PBS). A: total IgE level; B: PnE-specific IgG1 level; C: PnE-specific IgG2a level.

*: statistic differences between tested and control group (PnE/PBS) $(\mathrm{P}<0.05)$. 
higher level of peanut-specific IgG2a was found, which suggests the activation of Th1 lymphocytes. The antibody level of peanut-specific IgG2a in the pea legumin IT group (PL) was significantly higher than that in PE desensitized group and it was similar to that found in PnE desensitized group. In addition, an ELISPOT type B test was performed to determine the ability of production of specific IgG antibodies by lymphocytes isolated from spleen and stimulated with peanut proteins (Fig. 2). The highest number of B cells secreting specific antibodies was identified in groups desensitized with high doses of PE (1 mg) and PL (0.5 mg).

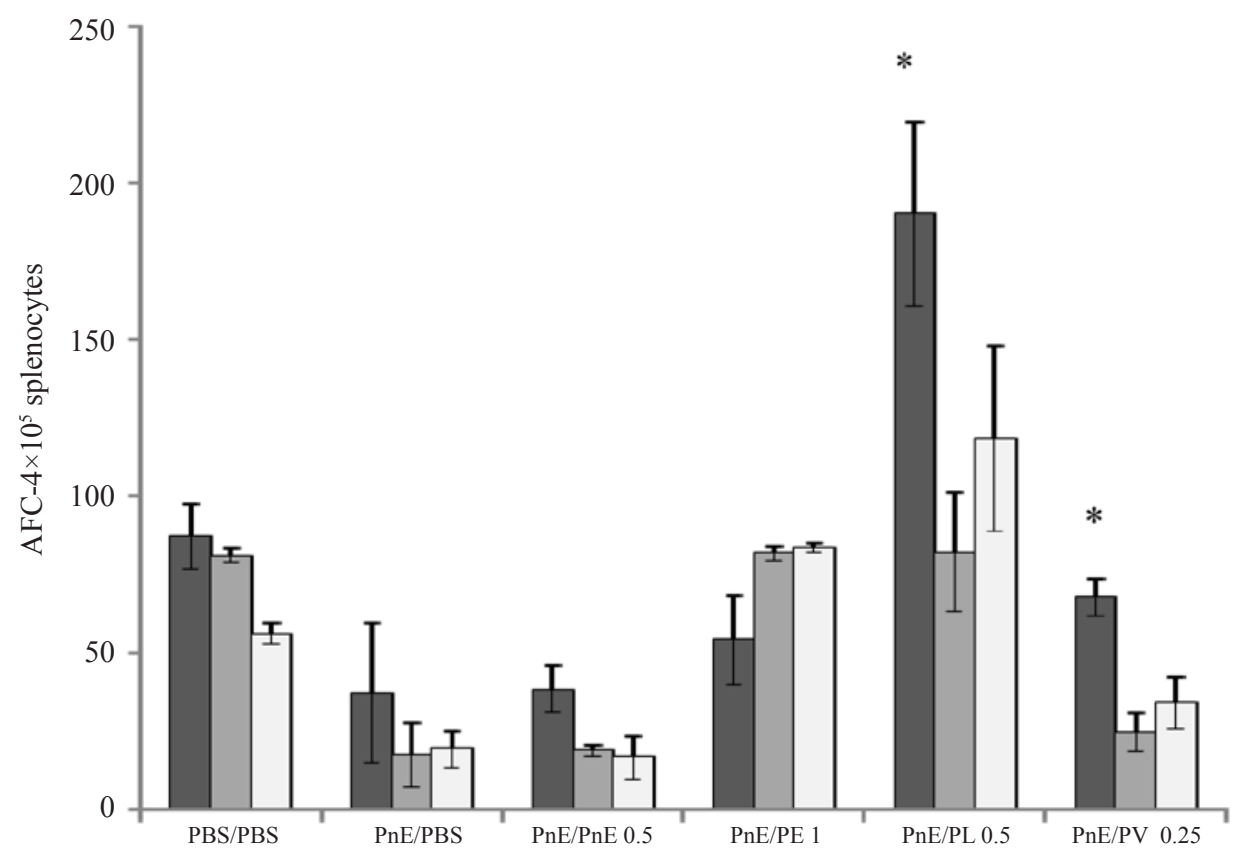

Fig. 2. The B-cells ELISPOT for IgG produced by splenocytes stimulated with peanut extract (a-PnE), peanut legumin $11 \mathrm{~S}$ - arachin (a-PnL); and peanut vicilin $7 \mathrm{~S}$ - conarachin (a-PnV). Pooled spleen cells isolated from peanut-sensitized mice $(\mathrm{PnE})$ after desensitization with: peanut proteins extract $0.5 \mathrm{mg}$ dose $(\mathrm{PnE} / \mathrm{PnE} 0.5)$; pea proteins extract $1 \mathrm{mg}$ dose (PnE/PE1); pea legumin $0.5 \mathrm{mg}$ dose (PnE/PL0.5); pea vicilin $0.25 \mathrm{mg}$ dose (PnE/PV0.25); placebo IT with PBS (PnE/PBS); native mice sensitized and desensitized with PBS (PBS/PBS);

$\square$ : a-PnE; $\square$ : a-PnL; $\square$ : a-PnV; *: statistic differences between tested and control group (PnE/PBS) $(\mathrm{P}<0.05)$.

STRAIT and co-workers (2006) reported that allergenic specific antibodies class G could block IgE in vivo at anaphylaxis by antigen cleavage and inhibition of Fc $\gamma$ RIIb receptors, but effective immunotherapy is related not only with production of blocking class $\mathrm{G}$ antibodies (especially IgG2a and IgG4). Allergenic immunotherapy induces shift in the cytokine profile from Th2 subpopulation (IL-4 and IL-5) towards Th1 subpopulation (IFN-gamma) (UERMÖSI et al., 2010). The most significant role in the development of oral tolerance is played by IL-10 and TGF- $\beta$ (Rolland et al., 2009). In addition, increased induction of allergen-specific CD4+T cells, demonstrating expression CD25 and Foxp3 (forhend box protein 3) (FREw, 2010), plays a function in the development of tolerance to $T$ cells as well. In addition to the main function of promoting the Th1-type response, IFN-gamma is also considered an early 


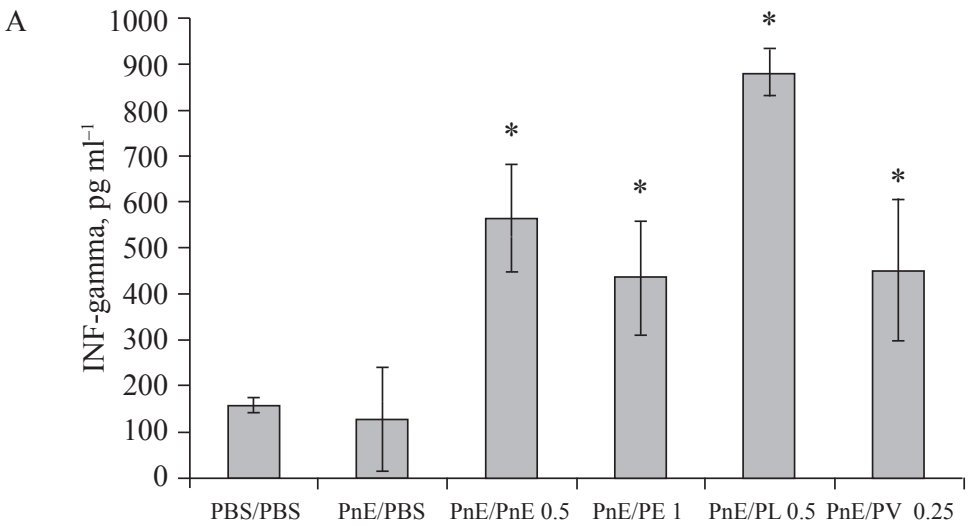

B

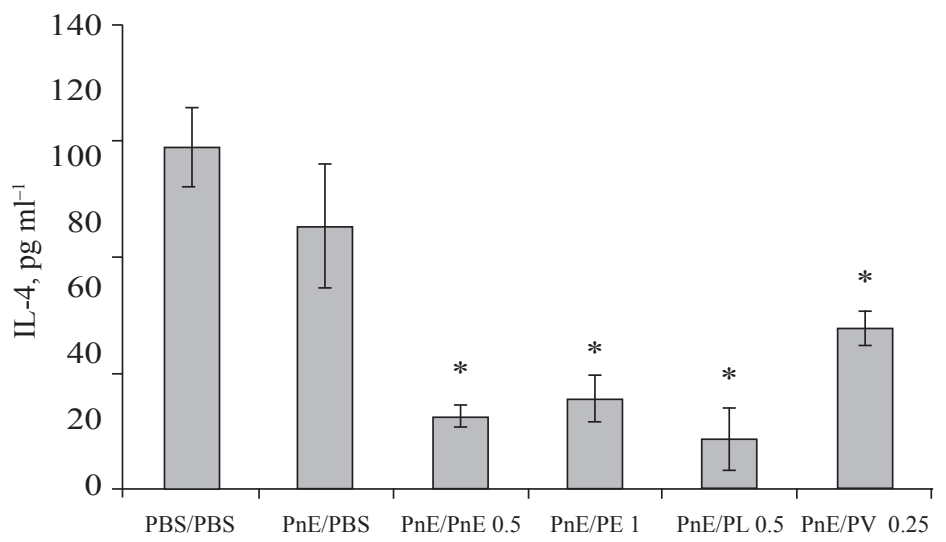

C

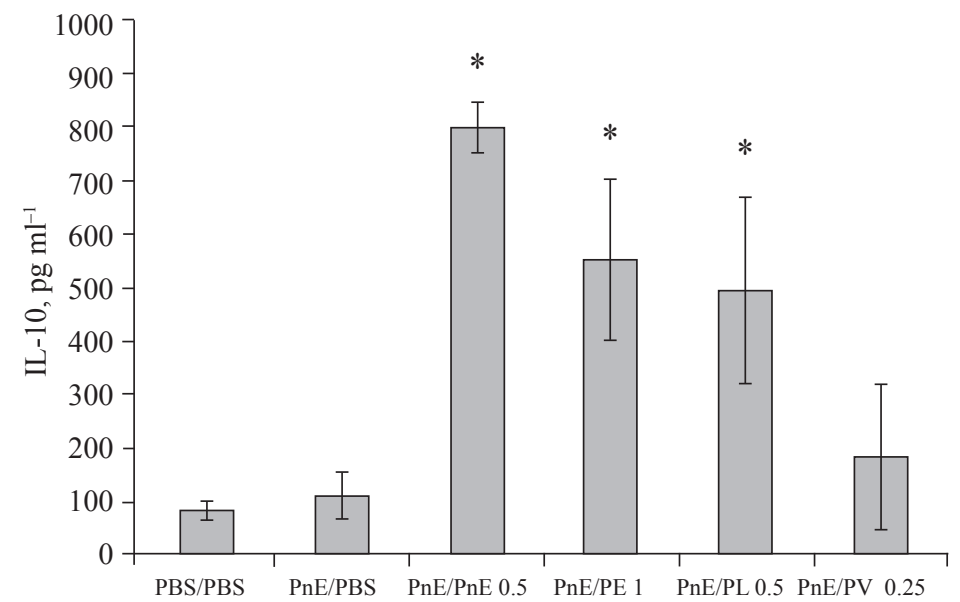

Fig. 3. Production of interleukins by splenocytes stimulated with peanut proteins extract (PnE).

Medium was the negative control and medium containing ConA the positive control (data not shown).

Pooled spleen cells isolated from peanut-sensitized mice $(\mathrm{PnE})$ after desensitization with: peanut proteins extract $0.5 \mathrm{mg}$ dose (PnE/PnE0.5); pea proteins extract $1 \mathrm{mg}$ dose (PnE/PE1); pea legumin 0.5 mg dose (PnE/PL0.5); pea vicilin $0.25 \mathrm{mg}$ dose (PnE/PV0.25); placebo IT with PBS (PnE/PBS); native mice sensitized and desensitized with PBS (PBS/PBS). A: INF-gamma level; B: IL-4 level; C: IL-10 level.*: statistic differences between tested and control group (PnE/PBS) $(\mathrm{P}<0.05)$. 
mediator of effector $\mathrm{T}$ cells and its immediate production is mostly connected with in vivo conditions at the beginning of the occurrence of memory $\mathrm{T}$ cells. Therefore, production of INF-gamma may be considered as a biomarker confirming the ability of antigens (added into culture, thus being mitogen) to activate T cells (AKDIs \& AKDIs, 2009). In our studies, IT with peanut proteins $(\mathrm{PnE})$ resulted in almost three-fold increase in the INF-gamma secretion in comparison to the control groups (Fig. 3). Surprisingly, high activity of T cells was observed in case of desensitized-groups with PL $(0.5 \mathrm{mg})$. In these groups, significant decrease in the ability of IL-4 secretion and increase in IL-10 level occurred simultaneously. IL-4 cytokine is the main regulator of the process in which B cells switch expression of immunoglobulin isotopes. At specific conditions, IL-4 can stimulate B cells for expression and secretion of IgG1 or IgE, directing mice response towards Th2-type response (allergy). The administration of pea legumin (PL) to mice reduced the PnE-specific secretion of IL-4 (Fig. 3) and thus lowered total IgE and PnE-specific IgG1 levels (Fig. 1).

The level of IL-10 can suggest increase of Treg cells activity, which plays significant role in food tolerance (AKDIS \& AKDIS, 2009). It is easy to interpret the role of IL-4, but the increased level of IL-10 is ambiguously explained (Hsu et al., 1992). Based on our observation, suppression of Th2 by IL-10 cytokines can result in the inhibition of allergy in Balb/c mice.

\section{Conclusion}

The desensitization method recommended by us with the use of pea proteins (especially legumin) can be an alternative to specific immunotherapy for people with strong allergic reaction to peanuts; however, this method still requires further studies. Immunotherapy with the use of pea proteins contributed to changes in response of $\mathrm{B}$ and $\mathrm{T}$ cells in mice. We believe that its application in humans can, at least, result in partial increase in the sensitivity threshold against peanut proteins, which can develop protection after their accidental consumption to some extent.

The work was financed by the Ministry of Science and Higher Education from the research funds in the years 2008-2011 as Research Project No: N N312 250734

\section{References}

AKdis, C.A. \& AKdis, M. (2009): Mechanisms and treatment of allergic disease in the big picture of regulatory T cells. J. Allergy Clin. Immunol., 123, 735-746.

Arps, V., Sudowe, S. \& KöLsch, E. (1998): Antigen dose-dependent differences in IgE antibody production are not due to polarization towards Th1 and Th2 cell subsets. Eur. J. Immonol., 28, 681-686.

Blumchen, K., Ulbricht, H., Staden, U., Dobberstein, K., Beschorner, J., De Oliveira, L.C., Shreffler, W.G., Sampson, H.A., Niggemann, B., Wahn, U. \& Beyer, K. (2010): Oral peanut immunotherapy in children with peanut anaphylaxis, J. Allergy Clin. Immunol., 126, 83-91.

FÆste, C.K. \& NAMORK, E. (2010): Differentiated patterns of legume sensitization in peanut-allergic patients. Fd Anal. Meth., 3, 357-362. 
Freitas, R.L., Ferreira, R.B. \& Teixeira, A.R. (2000): Use of a single method in the extraction of the seed storage globulins from several legume species. Application to analyze structural comparisons within the major classes of globulins. Int. J. Fd Sci. Nutr., 51, 341-352.

Frew, A.J. (2010): Allergen immunotherapy. J. Allergy Clin. Immunol., 125, 306-313.

Hourihane, J.B., Kliburn, S.A., Nordlee, J.A., Hefle, S.L., Taylor, S.L. \& Warner, J.O. (1997): An evaluation of the sensitivity of subjects with peanut allergy to very low doses of peanut protein: a randomized, double-blind, placebo-controlled food challenge study. J. Allergy Clin. Immunol., 100, 596-600.

Hsu, D.H., Moore, K.W. \& SpITs, H. (1992): Differential effects of IL-4 and IL-10 on IL-2-induced IFN-gamma synthesis and lymphokine-activated killer activity. Int. Immunol., 4, 563-569.

Khodoun, M., Strait, R., Orekov, T., Hogan, S., Karasuyama, H., Herbert, D.R., Kohl, J. \& Finkelman, F.D. (2009): Peanuts can contribute to anaphylactic shock by activating component. J. Allergy Clin. Immunol., 123, 342-351.

Kim, E.H., Bird, J.A., Kulis, M., Laubach, S., Pons, L., Shreffler, W., Steele, P., Kamilaris, J., Vickery, B. \& BurKs, A.W. (2011): Sublingual immunotherapy for peanut allergy: clinical and immunologic evidence of desensitization. J. Allergy Clin. Immunol., 127, 640-646.

Lee, S.Y., Huang, C.K., Zhang, T.F., Schofield, B.H., Burks, A.W., Bannon, G.A. \& Sampson, H.A. (2001): Oral administration of IL-12 suppresses anaphylactic reactions in a murine model of peanut hypersensitivity. Clin. Immunol., 101, 220-228.

Li, X.M., Serebrisky, D., Lee, S.Y., Huang, C.K., Bardina, L., Schofield, B.H., Stanley, J.S., Burks, A.W., Bannon, G.A. \& SAmpson, H.A. (2000): A murine model of peanut anaphylaxis: T- and B-cell responses to a major peanut allergen mimic human responses. J. Allergy Clin. Immunol., 106, 150-158.

Maddaloni, M., Staats, H.F., Mierzejewska, D., Hoyt, M., Robinson, A., Callis, G., Kozaki, S., Kiyono, H., McGhee, J.R., Fujhashi, K. \& Pascual, D.W. (2006): Mucosal vaccine targeting improves onset of mucosal and systemic immunity to botulinum neurotoxin A. J. Immunol., 177, 5524-5532.

Maleki, S.J., Kopper, R.A., Shin, D.S., Park, C.W., Compadare, C.M., Sampson, H., Burks, W. \& Bannon, G.A. (2000): Structure of the major peanut allergen Ara h 1 may protect IgE-binding epitopes from degradation. $J$. Immunol., 164, 5844-5849.

Oppenheimer, J.J., Nelson, H.S., Bock, S.A., Christensen, F. \& Leung, D.Y.M. (1992): Treatment of peanut allergy with rush immunotherapy. J. Allergy Clin. Immunol., 90, 256-262.

Pons, L., Ponnappan, U., Hall, R.A., Simpson, P., Cockrell, G., West, M., Sampson, H.A., Helm, R.M. \& Burks, A.W. (2004): Soy immunotherapy for peanut-allergic mice: Modulation of the peanut-allergic response. $J$. Allergy Clin. Immunol., 114, 915-921.

Rolland, J.M., Gardner, L.M. \& O’hehir, R.E. (2009): Allergen-related approaches to immunotherapy. Pharmacol. Therapeutics, 121, 273-284.

Savage, J.H., Kaeding, A.J., Matsui, E.C. \& Wood, R.A. (2010): The natural history of soy allergy. J. Allergy Clin. Immunol., 125, 683-686.

Strait, R.T., Morris, S.C. \& Finkelman, F.D. (2006): IgG-blocking antibodies inhibit IgE-mediated anaphylaxis in vivo trough both antigen interception and Fc gamma RIIb cross-linking. J. Clin. Invest., 116, 833-841.

Thyagarajan, A., Varshney, P., Jones, S.M., Sicherer, S., Wood, R., Vickery, B.P., Sampson, H. \& Burks, A.W. (2010): Peanut oral immunotherapy is not ready for clinical use. J. Allergy Clin. Immunol., 126, 31-32.

Uermösi, C.H., Beerli, R.R., Bauer, M., Manolova, V., Dietmeier, K., Buser, R.B., Kündig, T.M., Saudan, P. \& Bachmann, M.F. (2010): Mechanisms of allergen-specific desensitization. J. Allergy Clin. Immunol., 126, $375-383$. 